\title{
Strain Rate Effect of Size Variants and Tensile Behavior of $6082 T 6$ Aluminum during Deformation by Accumulative Roll Bonding
}

\author{
P. B. SOB \\ ${ }^{1}$ Department of Mechanical Engineering, Faculty of Engineering and Technology, \\ Vaal University of Technology, Vanderbijlpark, South Africa.
}

\begin{abstract}
The strain rate effect of size variants on tensile behavior of aluminum after deformation by ARB was investigated. The yield strength, ultimate strength and tensile toughness for size variants were all observed to increase with increase strain rates at different ranges for the size variants deformed by ARB. Different results of deformation on yield strength for revealed for sizes variants. Different results for size variants on tensile behavior was also revealed for different strain rate during ARB. It was shown that yield stress generally increased with decreasing grain size since this was accompanied by dislocation motion from grain interiors to grain boundaries and subsequent dislocation pile-ups at the grain boundaries. It was also observed that in the directions where the grain sizes increased and subsequently decreased due to grain breakage (i.e. $\mathrm{r} 1$ and $\mathrm{r} 3$ ), there were more material flow in those directions, accompanied by more dislocation motions, dislocation pile-ups, and hence larger grain boundary curvatures in those direction. It was also shown that the material suffers a breakage of the laminar structure due to surface stress and strain that is generated during grain refinement on the TD, ND and RD. The critical condition of grain breakage occurs when the size of the grain is very small during grain refinement. The motion of dislocations is characterized by easy slip without any blockage inside the grain and this creates sub-cells that result in dynamic recovery.
\end{abstract}

Keywords: Strain rate, size variants, deformation, aluminum and yield strength.

\section{INTRODUCTION}

Materials that have high yield strength high ductility are mostly used in automotive and aerospace application [1-6]. For the past decades now several design methods have been used to produced materials that have high yield strength and high ductility such as severe plastic deformation in accumulative roll bonding, transformation-induced plasticity [1-5], twinninginduced plasticity [2-6], and also the dual-phase [6,7]. For over the past decades high strength having very low density was achieved by adding $\mathrm{Al}(3-12 \mathrm{wt}$. \%). The produced materials have excellent mechanical properties, high yield strengths and uniform elongations [8-19]. It has been reported that most of the high yield strength are based on $\mathrm{Fe}-\mathrm{Al}-\mathrm{Mn}-\mathrm{C}$ alloy, and they consist of fcc austenite matrix, bcc ferrite matrix and finely dispersed k-carbides ( $(\mathrm{Fe}, \mathrm{Mn})$ in nano scale range. It was also revealed that the high yield strength material having a dualphase microstructure and ultrafine grains shown excellent mechanical properties.

Some material was reported to have high yield strength and large elongation. Some researcher attributed the high yield strength to the precipitation strengthening [20]. Some studies shown the stress- strain relationship between the constituent phases and their back-stress-induced strain hardening were revealed to play an important role in the process of severe plastic deformation for most materials during deformation [2122]. As such these materials can be considered as a perfect candidate for the process of advanced impact-tolerant structures in automotive and other related industry due to their excellent mechanical properties specifically their yield strength.

Generally, most plastic flow behaviors during grain refinement and their corresponding deformation mechanisms are greatly dependent on the loading rate of the material during deformation [23-44]. It is also reported that the resistance to plastic deformation or plasticity in severe plastic deformation is a rate-controlling process that is affected strain rate [23-30]. However, the quasi- static tensile behaviors and their dynamic behaviors at high strain rates have been studied and well characterized in previous research findings [1-50]. In this research findings there are limited experimental data on various deformed material at the intermediate strain rates [51-55], which is a vital transitional region in application such as automobile industry due to the fact that vehicle crushing often happens during car operation and in this strain rate range or within an even higher strain rate range during operation.

Therefore, the potentiality and applications for materials applicable in the automotive industry require a comprehensive and details understanding of the deformation physics subjected to their dynamic loading at intermediate strain rates during deformation. However, in high yield strength microstructure their strain rate sensitivity is quite different and therefore the loading rate can affect the stress/strain relationship. Since strain rate effect on material deformation is still undefined. The tensile strength of the produced material must also be tested if it can withstand the desired load it was produced to withstand during tensile loading condition. Due to this research gap series 
International Journal of Engineering Research and Technology. ISSN 0974-3154, Volume 13, Number 8 (2020), pp. 1823-1828

(C) International Research Publication House. https://dx.doi.org/10.37624/IJERT/13.8.2020.1823-1828

of uniaxial tensile tests over a range of strain rates have been conducted on aluminum after severe plastic deformation by ARB.

Their strain rate effect on flow behavior after ARB process study. This was to reveal the results that affect strain rates and tensile loading condition in materials used in automotive industry.

\section{MATERIALS AND METHODS}

The material was deformed by ARB processing routes. During experimentation the 6082T6 Aluminum was forced or fed through the rotating shafts. The rotating shafts gripped the 6082T6 aluminum sample and forced the sample through the rollers in the first pass. The deformed 6082T6 aluminum was cut into two pieces and stacked together. Before stacking, the entire surface of the strips was wire-brushed (i.e. using stainless steel brush) and degreased with tetrachloroethylene to achieve good bonding. The materials were joined together in the corners using aluminum wires and subsequently rolled. The whole sequence of "rolling, cutting, face-brushing, degreasing and stacking" was repeated again for several "passes" until nanomaterials with required characteristics were obtained. The samples with the deformed microstructures were examined using Transmission Electron Microscopy (TEM) to obtain lengths along the major axis $\mathrm{r} 3$, semi major axis $\mathrm{r} 1$ and semi minor axis $\mathrm{r} 2$. Tensile test was also performed to test the tensile load the produced material can withstand.

\section{SAMPLE DESIGN FOR MECHANICAL TESTING (TENSILE TESTING)}

In order to compare properties of materials deformed after different passes during grain refinement, it was necessary to design the samples for tensile testing as shown in figure 1.

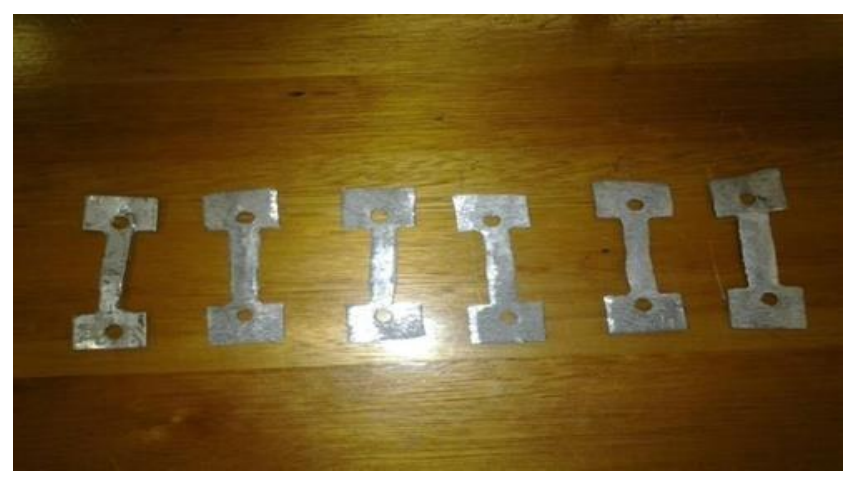

Figure 1: Dog bone samples designed for mechanical testing.

In order to contain the little sample geometry, the dog bones were designed using the measurement of the gripping heads in which the dog bones could easily fit and screw into the universal testing machine as shown in figure 1 . The actual setup procedure for tensile test is given as follows. Before each testing period, the upper and lower grips are protected with the use of an alignment guide and alignment screws. The sample was clamped on both clamp members that were screwed to the lower and upper members of the universal testing machine.

\section{STRESS TESTING (MECHANICAL TESTING) AND DATA CAPTURING}

The yield stress was measured during the deformation of nanostructured materials. The yield stress incurred by the dog bone samples were measured as shown in fig.10. The materials were subjected to longitudinal loading. Before experimentations by ARB the sample yield stress was measured and the sample for microscopic examination was removed for microscope study. After each processing route by $\mathrm{ARB}$, a section of the material was cut for microscopic observation and tensile testing. The results of microscopic examination are also analysis to the strain activities during deformation. The section of the materials taken for tensile testing was used to measure the yield stress of the materials in the different experimental cycles by ARB

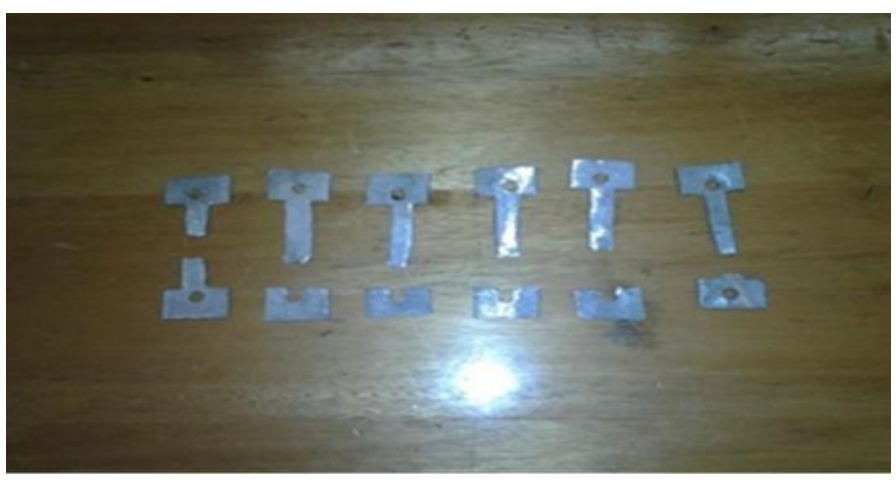

Figure 2: Dog bone samples after tensile test

\section{MICROSCOPE STUDY AND MODELLING}

The initial sample with the deformed materials were examined using TEM. Standard TEM thin foils $3 \mathrm{~mm}$ in diameter were prepared by electrolytic twin-jet polishing $($ at $-30 \circ \mathrm{C}, 30 \mathrm{~V})$ in Struers Tenupol 2 filled with $6 \%$ solution of perchloric acid in methanol. The observations were carried out at

$200 \mathrm{kV}$ with JEOL JEM 2000FX microscope equipped with an X-ray energy dispersive spectrometer (XEDS) LINK AN 10 000. After the microscopy analysis the relevant models were designed based on the microscopy analysis.

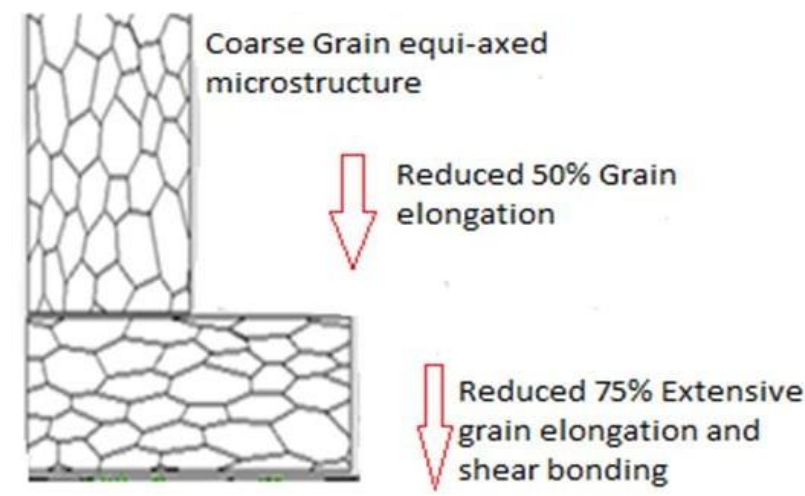

(a) 


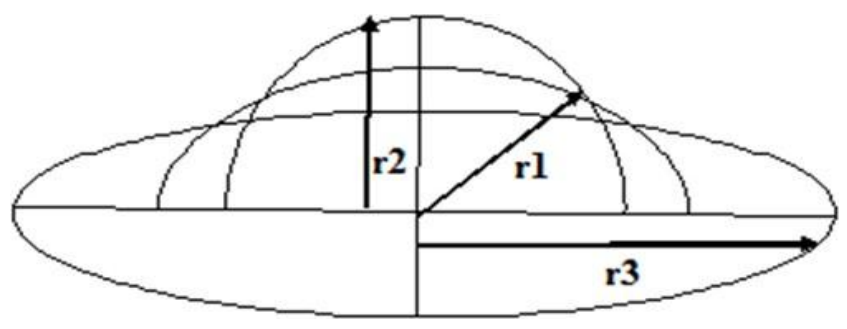

(b)

Figure 3(a) deformed materials after ARB cycles (b) Schematic of elongated grains due to deformation in 3-D grain.

During microscopy process the following observation led to the derivation of the relevant models. It is observed based on experimentation and represented in Fig. $3(a-b)$ that the longer grains tend to break along a common grain boundary to form multiple grains. This grain breakage dramatically reduces the lengths of the grains along the semi major axis and the major axis directions, which start to lengthen again. This grain lengthening-and- breakage process repeats itself over and over leading to the effective lengths of the semi major axis and major axis getting shorter when compared with the starting lengths. It can be said that the evolutions of the semi major lengths and the major axis lengths are stochastic jump processes in nature. This activity affected grain elongation during grin refinement shown in equation (1).

$$
\text { Elongation }=\frac{3 \pi r_{0} r_{1}^{4}}{r_{2} r_{3} r^{3}}\left(r-r_{0}\right)
$$

By employing the different experimental observation for $r, r_{1}$, $r_{2}$ and $r_{3}$ during grain refinement the following set of conditions is established for 3-D grain. Since r, involve increase and instantaneous decrease by breaking. The expression of $r_{1}$ during grain refinement can be represented

$d r_{1}=M\left(\frac{1}{r_{c 1}}-\frac{1}{r_{1}}\right) d t+r_{1}^{\left(\frac{1}{2}\right)} D d W(t)-A\left(r_{1}\right)\left(V_{1}\right) d(t)$

where $r_{c 1}=$ the local critical grain size, $\mathrm{A}$ and $D$ are Constants, $\mathrm{dW}(\mathrm{t})=$ increment of the wiener process, $V_{1}=$ define rate of grain $\tau_{1} r_{1}^{2}$ breakage process, $\mathrm{M}=\mathrm{M}_{0}\left(1+\mathrm{CD} \quad\left(r_{12} / r_{1}^{3}\right)\right)$, $\mathrm{CD}=4(\mathrm{Hm})\left(\mathrm{h}_{0}\right) /((\mathrm{k})(\mathrm{T})), \mathrm{T}_{\mathrm{m}}=\mathrm{T}\left\{\ln \left(\mathrm{m}_{01} / \mathrm{m}\right)\right.$ and $\mathrm{M}_{0}=\mathrm{M}_{01} \exp \{-$ $\left.\mathrm{T}_{\mathrm{m}}(\mathrm{inf}) / \mathrm{T}\right\}$

For $\mathrm{r}_{2}$ that decreases as a fraction of $\mathrm{r}$ during grain refinement, $\mathrm{r}_{2}$ can be represented

$$
d r_{2}=\text { Ratio }_{2}(d r)
$$

It was experimentally observed during grain refinement that $r_{3}$ decreases at a lower rate than $r_{1}$. The model of $r_{3}$ can be represented as a proportion of $r_{1}$ given as

$$
d r_{3}=\text { Ratio }_{1}\left(d r_{1}\right)
$$

Since the equivalent radius $r$ decreases continuously during grain refinement $r$ can be represented

$$
d r=-Q(r) d t+C d W(t)
$$

where $\mathrm{Q}$ and $\mathrm{C}$ are constants

The modified expression of the HPR to reveal the Reverse HPR given by Zhao (Zhao et al. 2006:472-474) which was later modified to consider the stochastic nature of grain size is given by

$$
\sigma(r)=\sigma_{0}^{\prime}+A\left(r^{-\frac{1}{2}}\right)-B\left(r^{-1}\right)-C\left(r^{-\frac{3}{2}}\right)
$$

where is bulk yield stress, is HPR proportionality constant, $\mathrm{K}$ and $\sigma_{0}^{\prime}=\sigma_{0}+K_{t} A=K_{d} B=K_{t}\left[2 h H_{m} / R T_{r}\right] C=K_{d}\left[2 h H_{m} / R T_{r}\right]_{t}$ is a constant, $\mathrm{h}$ is atomic diameter in the case of metal, $\mathrm{H}_{\mathrm{m}}$ is the bulk melting enthalpy, $\mathrm{R}$ is ideal gas constant, $\mathrm{T}_{\mathrm{r}}$ is the room temperature, $K_{d}>100 K_{t}$ and $\sigma_{0}>10 K_{t}$

The models of strain for nanocrystalline material is defined from the different grain size variants in expression (2-5) are given as

$$
d \varepsilon_{r}=d[d r / r]=d(-Q(r) d t+C d W(t))
$$

$$
d \varepsilon_{1}=d\left[d r_{1} / r_{1}\right]=d\left(M\left(1 / r_{1 c}\left(1 / r_{1}\right)-1 / r_{1}^{2}\right) d t+D d W(t\right.
$$

$\left.r_{1}\right]=d\left(M\left(1 / r_{1 c}\left(1 / r_{1}\right)-1 / r_{1}^{2}\right) d t+D d W(t)-A\left(V_{1}\right) d(t)\right)$

$$
d \varepsilon_{2}=d\left[d r_{2} / r\right]=d\left(\operatorname{Ratio}_{2}(d r)\right)
$$

$$
d \varepsilon_{3}=d\left[d r_{3} / r_{1}\right]=d\left(\text { Ratio }_{1}\left(d r_{1}\right)\right)
$$

The models of strain rate for nanocrystalline material is defined from the different strain variants in expression (7-10) are given as

$$
\begin{gathered}
\varepsilon_{r r}=\frac{d\lfloor d r / r\rfloor}{d t}=\frac{d[(-Q(r)) d t+C d W(t)]}{d t} \\
\varepsilon_{r 1}=\frac{d\left[\frac{d r_{1}}{r_{1}}\right]}{d t}=\frac{\left.d\left(M\left(\frac{1}{r_{1 c}}\right)\left(\frac{1}{r_{1}}\right)-\frac{1}{r_{1}^{2}}\right) d t+D d W(t)-A\left(V_{1}\right) d(t)\right]}{d t} \\
\varepsilon_{r 2}=\frac{d\left[\frac{d r_{2}}{r}\right]}{d t}=\frac{d\left[\text { Ratio }_{2}(d r)\right]}{d t}
\end{gathered}
$$


International Journal of Engineering Research and Technology. ISSN 0974-3154, Volume 13, Number 8 (2020), pp. 1823-1828

(C) International Research Publication House. https://dx.doi.org/10.37624/IJERT/13.8.2020.1823-1828

$$
\varepsilon_{r 3}=\frac{d\left[\frac{d r_{3}}{r_{1}}\right]}{d t}=\frac{d\left[\operatorname{Ratio}_{1}\left(d r_{1}\right)\right]}{d t}
$$

The derived expression of elongation is used to test the impact of elongation on yield stress, strain and strain rate. Equations (1) to (14) are solved simultaneously using Engineering Equation Solver software (F-Chart Software, Madison, $\mathrm{W} 153744$, USA) and results presented (GB) mobility function, $C D=4(H m)(h 0) /(k)(T)), T_{m}=T\{\ln (m 01 / m)$ and $M 0=$ M01exp $\left\{-T_{m}(\right.$ inf $\left.) / T\right\}=$ initial grain boundary mobility constant, $\mathrm{dW}(\mathrm{t})$ is of wiener process and $\mathrm{dN}(\mathrm{t})$ is the number of coalescence events within an infinitesimal time interval.

Since $r_{3}$ decreases as a fraction or proportion of $r_{l}$ during grain refinement, $r_{3}$ can be represented Ratio2 $=1.071$ and $\tau_{1}=$ 0.000008 . The additional data were obtained through curve fitting of the empirical data from the different measures of the sizes from table: 1 . The obtained results are presented in the plots and discussed below.

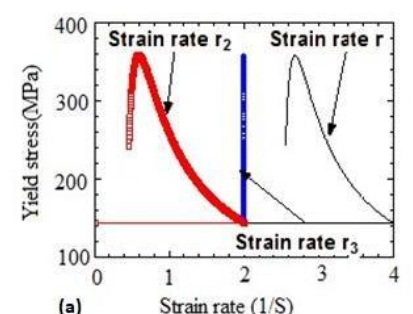

(a)

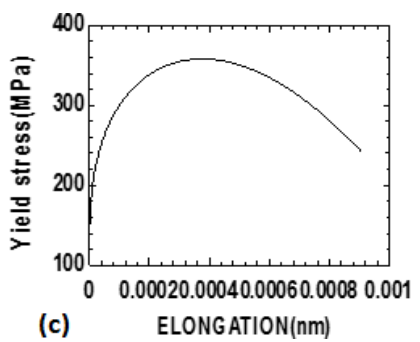

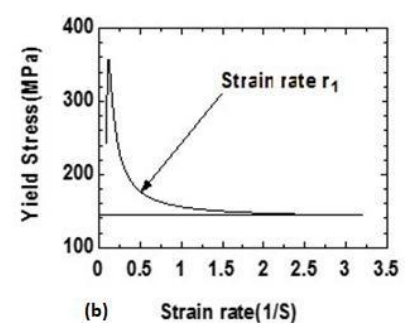

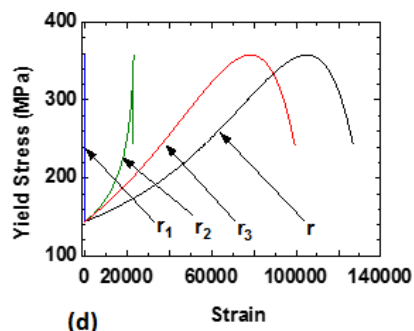

(d) showing more rapid enhanced properties. Since elongation can be termed lengthening, it can be concluded that materials with elongated grains have more enhanced properties which rapidly drop with continuous lengthening of the grains. The reason for the subsequent decrease in yield stress with further increase in elongation was due to the fact that there came a point where the elongation became extremely large with very small changes in grain size leading to low plastic deformation and low materials hardness. Extreme plastic straining led to distorted structures where the grain boundaries and grain curvatures were in "nonequilibrium" states. Furthermore, it has been revealed as shown in Fig. 3 (d) that different critical grain sizes exist for $r 1, r 2, r 3$ and $r$, but at the same yield stress value.

The different strain rates observed in Fig. 3(a) and (b) shows a general trend. It should be observed that in order to increase the material yield stress, the rate of straining of the material had to be reduced which was in line with the observations made by other researchers (Barnett, Estrin, Hodgson \& Sabirove, 2009:181). The reduction in strain rate was to allow the material to relax and accommodate more plastic strain. Furthermore, it was observed that indefinite reduction in strain rate did not lead to more property enhancement since it was becoming difficult for the material to deform.

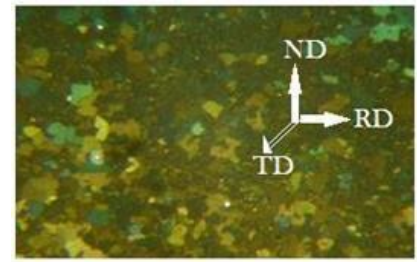

(a)

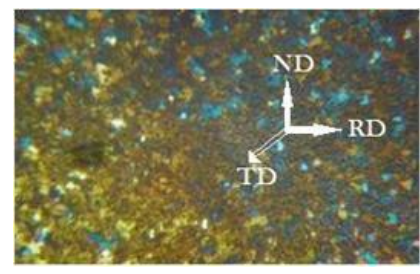

(c)

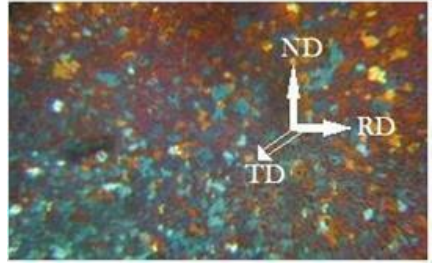

(b)

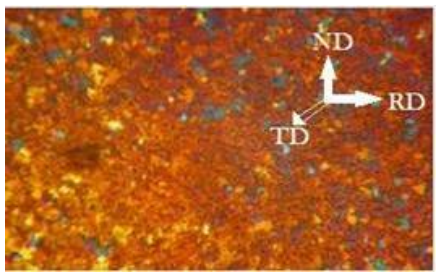

(d)
Figure 3 (a-d): Plots of yield stress as a function of strain rate

From Fig.19 (a-b) it is observed that yield stress evolved as predicted by Hall-Petch to Reversed Hall- Petch Relationship (HPR-RHPR) when measured as functions of elongation, strain and strain rate. The yield stress generally increased with decreasing grain size since this was accompanied by dislocation motion from grain interiors to grain boundaries and subsequent dislocation pile-ups at the grain boundaries. It was observed that in the directions where the grain sizes increased and subsequently decreased due to grain breakage (i.e. 1 and r3), there were more material flow in those directions, accompanied by more dislocation motions, dislocation pileups, and hence larger grain boundary curvatures in those direction.

The yield stress when measured as a function of grain size and strain with grain size measured along the $\mathrm{r} 1$ and $\mathrm{r} 3$ directions

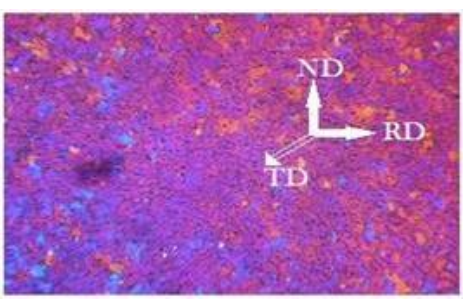

(e)

Figure 4: TEM observations after different experimental cycles during grain refinement.

During investigation of the strains on the microstructures, it was observed after a small number of experimental cycles that there is a mixture of grains that have not deformed and grains that suffer a reduction in thickness and an elongated morphology oriented in the RD as shown in Figure 4 (a). After 
several experimental cycles the orientation of the grains can be seen as shown in Figure 4 (b). They are two different types of grains coexisting in Figure 4 (b), the equiaxial and morphologically elongated grains. After further experimental cycles severe reduction of thickness of grain size is shown in Figure 4 (c). The grain boundaries become less visible since the grains are thinner and elongated in the rolling direction as shown in Figure 4 (c). As the number of experimental cycles increase the microstructures show a more uniform structure as shown in Figure 4 (d). The material strain is very high due to many experimental cycles of grain refinement. The dislocations density is high due to the high deformation suffered by the material during continuous straining of the material. As the number of experimental cycles increase the microstructure obtained is shown in Figure 4 (e), from where it is possible to observe recrystallization. The material is continuously recrystallizing as observed in Figure 4 (e). This is characterized by grain subdivision of ultra-fine grains which are recovered to form new ultra-fine grains with migration of grain boundaries. The material suffers a breakage of the laminar structure due to surface stress and strain that is generated during grain refinement on the TD, ND and RD. The critical condition of grain breakage occurs when the size of the grain is very small during grain refinement. When the size of the grain is stable, the movement of free dislocations is shorter and the formation of dislocation in the grain is limited. The motion of dislocations is characterized by easy slip without any blockage inside the grain and this creates sub-cells that result in dynamic recovery. As more grain refinement takes place grain growth occurs due to adiabatic warming. Table 2 shows the results of tensile test.

Table 2: Data from Mechanical testing (Tensile test) and Experimental cycles

\begin{tabular}{lll}
\hline \multicolumn{1}{c}{ Cycles } & Elongation [nm] & yield Stress [MPa] \\
Initial Pass & $7.856 \mathrm{E}-08$ & 143 \\
Passes & $9.163 \mathrm{E}-08$ & 220 \\
Passes & $4.502 \mathrm{E}-07$ & 350 \\
Passes & 0.00013 & 150 \\
\hline
\end{tabular}

It was observed that the yield stress increases with an increasing number of experimental cycles during experimentation as shown in table 2 . The increase in yield stress during tensile testing revealed that nanomaterials have more enhanced properties when compared with conventional materials. During material deformation by ARB cycles, the material is subjected to straining. The straining in the material increases since several experimental cycles were performed. The increase in strain during experimentations impact the yield stress and elongation. The elongation was obtained by measuring the different directions of $r 1, r 2, r 3$ and $r$ in the microstructures during deformation of the materials. It was also observed that continuous refinement did not lead to property enhancement as the material strength later decreased with an increasing number of passes as shown in table 2 . The theoretical results agree with experimental results since there exists some correlation between both theoretical and experimental results as demonstrated in this paper. Therefore, the produced nanomaterials by ARB has significant yield strength and it can be used in automotive industry.

\section{CONCLUSION AND RECOMMENDATION}

The current study was aimed at studying the strain rate effect and tensile behavior of aluminum and their application to automotive industry. To achieve this tensile test, ARB experimental, modelling and microscopy analysis was done. The produced material was subjected to tensile testing and the strain rate models were derived based on size. The microstructure analysis was done to validate the dislocation activities and the degree of strain rate of the produced materials. The following fact was theoretically revealed and validated experimentally.

The yield stress generally increased with decreasing grain size since this was accompanied by dislocation motion from grain interiors to grain boundaries and subsequent dislocation pileups at the grain boundaries. It was observed that in the directions where the grain sizes increased and subsequently decreased due to grain breakage (i.e. $\mathrm{r} 1$ and $\mathrm{r} 3$ ), there were more material flow in those directions, accompanied by more dislocation motions, dislocation pile-ups, and hence larger grain boundary curvatures in those direction. It can be concluded that materials with elongated grains have more enhanced properties which rapidly drop with continuous lengthening of the grains. The reduction in strain rate was to allow the material to relax and accommodate more plastic strain. Furthermore, it was observed that indefinite reduction in strain rate did not lead to more property enhancement since it was becoming difficult for the material to deform. The material suffers a breakage of the laminar structure due to surface stress and strain that is generated during grain refinement on the TD, ND and RD. The critical condition of grain breakage occurs when the size of the grain is very small during grain refinement. The motion of dislocations is characterized by easy slip without any blockage inside the grain and this creates sub-cells that result in dynamic recovery.

\section{ACKNOWLEDGEMENT}

This material is based on the work which is supported financially by the Vaal University of Technology (VUT).

\section{REFERENCES}

[1] Fischer, F.D.; Reisner, G.; Werner, E.; Tanaka, K.; Cailletaud, G.; Antretter, T. A new view on transformation induced plasticity (TRIP). Int. J. Plast. 2000, 16, 723-748. [CrossRef]

[2] Grässel, O.; Krüger, L.; Frommeyer, G.; Meyer, L.W. High strength $\mathrm{Fe}-\mathrm{Mn}-(\mathrm{Al}, \mathrm{Si})$ TRIP/TWIP steels development-properties-application. Int. J. Plast. 2000, 16, 1391-1409. [CrossRef] 
International Journal of Engineering Research and Technology. ISSN 0974-3154, Volume 13, Number 8 (2020), pp. 1823-1828

(C) International Research Publication House. https://dx.doi.org/10.37624/IJERT/13.8.2020.1823-1828

[3] Frommeyer, G.; Brüx, U.; Neumann, P. Supra- ductile and high-strength manganese-TRIP/TWIP steels for high energy absorption purposes. ISIJ Int. 2003, 43, 438-446. [CrossRef]

[4] Bouaziz, O.; Allain, S.; Scott, C. Effect of grain and twin boundaries on the hardening mechanisms of twinninginduced plasticity steels. Scr. Mater. 2008, 58, 484-487. [CrossRef]

[5] Kang, S.; Jung, Y.S.; Jun, J.H.; Lee, Y.K. Effects of recrystallization annealing temperature on carbide precipitation, microstructure, and mechanical properties in $\mathrm{Fe}-18 \mathrm{Mn}-0.6 \mathrm{C}-1.5 \mathrm{Al}$ TWIP steel. Mater. Sci.

[6] Eng. A 2010, 527, 745-751. [CrossRef]

[7] Metals 2018, 8, 1112 of 14

[8] Son, Y.I.; Lee, Y.K.; Park, K.T.; Lee, C.S.; Shin, D.H. Ultrafine grained ferrite-martensite dual phase steels fabricated via equal channel angular pressing: Microstructure and tensile properties. Acta Mater. 2005, 53, 3125-3134. [CrossRef]

[9] Calcagnotto, M.; Adachi, Y.; Ponge, D.; Raabe, D. Deformation and fracture mechanisms in fine- and ultrafine-grained ferrite/martensite dual-phase steels and the effect of aging. Acta Mater. 2011, 59, 658- 670. [CrossRef]

[10] Jiang, S.H.; Wang, H.; Wu, Y.; Liu, X.J.; Chen, H.H.; Yao, M.J.; Gault, B.; Ponge, D.; Raabe, D.; Hirata, A.; et al.

[11] Ultrastrong steel via minimal lattice misfit and highdensity nanoprecipitation. Nature 2017, 544, 460

[12] 464. [CrossRef] [PubMed]

[13] Raabe, D.; Springer, H.; Gutierrez-Urrutia, I.; Roters, F.; Bausch, M.; Seol, J.B.; Koyama, K.; Choi, P.P.; Tsuzaki, K. Alloy design, combinatorial synthesis, and microstructure-property relations for low- density $\mathrm{Fe}-$ Mn-Al-C austenitic steels. JOM 2014, 66, 1845-1856. [CrossRef]

[14] Raabe, D.; Tasan, C.C.; Springer, H.; Bausch, M. From high-entropy alloys to high-entropy steels. Steel Res. Int. 2015, 86, 1127-1138. [CrossRef]

[15] Frommeyer, G.; Bruex, U. Microstructures and mechanical properties of high strength $\mathrm{Fe}-\mathrm{Mn}-\mathrm{Al}-\mathrm{C}$ light-weight TRIPLEX steels. Steel Res. Int. 2006, 77, 627-633. [CrossRef]

[16] Rana, R.; Lahaye, C.; Ray, R.K. Overview of lightweight ferrous materials: Strategies and promises. JOM 2014, 66, 1734-1746. [CrossRef]

[17] Kim, H.; Suh, D.W.; Kim, N.J. Fe-Al-Mn-C lightweight structural alloys: A review on the microstructures and mechanical properties. Sci. Technol. Adv. Mater. 2013, 14, 014205. [CrossRef] [PubMed]

[18] Sohn, S.S.; Song, H.; Suh, B.C.; Kwak, J.H.; Lee, B.J.; Kim, N.J.; Lee, S. Novel ultra-high- strength (ferrite + austenite) duplex lightweight steels achieved by fine dislocation substructures (Taylor lattices), grain refinement, and partial recrystallization. Acta Mater.
2015, 96, 301-310. [CrossRef]

[19] Gutierrez-Urrutia, I.; Raabe, D. Multistage strain hardening through dislocation substructure and twinning in a high strength and ductile weight-reduced $\mathrm{Fe}-\mathrm{Mn}-$ Al-C steel. Acta Mater. 2012, 60, 5791-5802. [CrossRef]

[20] Gutierrez-Urrutia, I.; Raabe, D. Influence of Al content and precipitation state on the mechanical behavior of austenitic high-Mn low-density steels. Scr. Mater. 2013, 68, 343-347. [CrossRef]

[21] Yoo, J.D.; Hwang, S.W.; Park, K.T. Factors influencing the tensile behavior of a $\mathrm{Fe}-28 \mathrm{Mn}-9 \mathrm{Al}-0.8 \mathrm{C}$ steel. Mater. Sci. Eng. A 2009, 508, 234-240. [CrossRef]

[22] Hwang, S.W.; Ji, J.H.; Lee, E.G.; Park, K.T. Tensile deformation of a duplex $\mathrm{Fe}-20 \mathrm{Mn}-9 \mathrm{Al}-0.6 \mathrm{C}$ steel having the reduced specific weight. Mater. Sci. Eng. A 2011, 528, 5196-5203. [CrossRef]

[23] Wu, Z.Q.; Ding, H.; An, X.H.; Han, D.; Liao, X.Z. Influence of $\mathrm{Al}$ content on the strain-hardening behavior of aged low density $\mathrm{Fe}-\mathrm{Mn}-\mathrm{Al}-\mathrm{C}$ steels with high $\mathrm{Al}$ content. Mater. Sci. Eng. A 2015, 639, 187-191. [CrossRef]

[24] Kim, S.H.; Kim, H.; Kim, N.J. Brittle intermetallic compound makes ultrastrong low- density steel with large ductility. Nature 2015, 518, 77-79. [CrossRef] [PubMed]

[25] Yang, M.X.; Yuan, F.P.; Xie, Q.G.; Wang, Y.D.; Ma, E.; $\mathrm{Wu}$, X.L. Strain hardening in Fe-16Mn-10Al-0.86C$5 \mathrm{Ni}$ high specific strength steel. Acta Mater. 2016, 109, 213-222. [CrossRef]

[26] Wang, W.; Zhang, H.S.; Yang, M.X.; Jiang, P.; Yuan, F.P.; Wu, X.L. Shock and spall behaviors of a high specific strength steel: Effects of impact stress and microstructure. J. Appl. Phys. 2017, 121, 135901. [CrossRef]

[27] Nemat-Nasser, S.; Guo,W.G. Thermomechanical response of DH-36 structural steel over a wide range of strain rates and temperatures. Mech. Mater. 2003, 35, 1023-1047. [CrossRef]

[28] Mishra, A.; Martin, M.; Thadhani, N.N.; Kad, B.K.; Kenik, E.A.; Meyers, M.A. High-strain-rate response of ultra-fine-grained copper. Acta Mater. 2008, 56, 2770 2783. [CrossRef]

[29] Wei, Q. Strain rate effects in the ultrafine grain and nanocrystalline regimes-Influence on some constitutive responses. J. Mater. Sci. 2007, 42, 1709 1727. [CrossRef]

[30] Subhash, G. The co 